\title{
Relationship Between Waist Circumference, Epicardial Fat Thickness, and Genders
}

We would like to thank Engin $\mathrm{M}^{\left[{ }^{[1]}\right.}$ for his kind interest and considerations on our article $e^{[2]}$. He pointed out that the waist circumference (WC) should be evaluated separately for men and women ${ }^{[1]}$. This is indeed a valid suggestion. In our study, we did not analyze WC separately for men and women, we evaluated the total population. We aimed only to assess epicardial fat thickness (EFT) and the $\mathrm{CHA}_{2} \mathrm{DS}_{2}$-VASC score including cardiovascular risk factors.

Abdominal obesity (AO) is associated with an increased risk of cardiovascular disease. WC, which is an indicator of $\mathrm{AO}$, has been shown to correlate with $\mathrm{EFT}^{[3]}$. In the study by Jeong et al., similarly to ours, no separate assessment was made between the gender ${ }^{[3]}$. In our study, it has been shown similar results. According to the Jeong et al. suggestion, when the genders were evaluated separately, it was found that both men and women were similarly correlated $(r=0.218, P=004$ and $r=0.216$, $P=0.05$, respectively ${ }^{[3]}$. Our results showed that when the gender was evaluated separately, the correlation coefficient did not change much, but there could be a change in significance. This situation can be explained by using numerical variables instead of categorical variables, such as gender, while calculating the Spearman's rank correlation coefficient and performing Pearson's correlation analysis ${ }^{[4]}$.

We therefore agree that larger-scale studies should be conducted to clarify the difference of EFT and WC between the genders. Consequently, gender-based studies in the following years may bring a more explanatory view to this situation.

\section{Fatih Aksoy ${ }^{1}, \mathrm{MD}$}

(D) https://orcid.org/0000-0002-6480-4935

'Department of Cardiology, Süleyman Demirel Faculty of Medicine, Isparta, Turkey.

E-mail:dr.aksoy@hotmail.com

\section{Serdar Güler ${ }^{2}$, MD}

${ }^{2}$ Department of Cardiology, Acıpayam State Hospital, Denizli, Turkey.

\section{REFERENCES}

1. Engin M. The relation between echocardiographic epicardial fat thickness and CHA2DS2-Vasc score in patients with sinus rhythm. Braz J Cardiovasc Surg. 2020;35(3):406. doi:10.21470/1678-9741-2020-0017.

2. Aksoy F, Guler S, Kahraman F, Oskay T, Varol E. The relation between echocardiographic epicardial fat thickness and CHA2DS2-VASC score in patients with sinus rhythm. Braz J Cardiovasc Surg. 2019;34(1):41-7. doi:10.21470/1678-9741-2018-0230.

3. Jeong JW, Jeong MH, Yun KH, Oh SK, Park EM, Kim YK, et al. Echocardiographic epicardial fat thickness and coronary artery disease. Circ J. 2007;71(4):536-9. doi:10.1253/circj.71.536.

4. de Winter JC, Gosling SD, Potter J. Comparing the Pearson and Spearman correlation coefficients across distributions and sample sizes: a tutorial using simulations and empirical data. Psychol Methods. 2016;21(3):27390. doi:10.1037/met0000079. 